\title{
Resenha
}

\section{Psicanálise e poder: constituição e estrutura}

\author{
Vinicius Darriba ${ }^{1}$
}

Dunker, C. (2011). Estrutura e constituição da clínica psicanalítica: uma arqueologia das práticas de cura, psicoterapia e tratamento. São Paulo, SP: Annablume.

Do início ao fim do expressivo livro de Christian Dunker, não se deve perder de vista que se tratar de uma interrogação sobre o poder na constituição e na estrutura da clínica psicanalítica. A questão relativa à forma de poder aí implicada resta inarticulada quando a experiência da psicanálise é assimilada a uma clínica no sentido da ciência médica moderna, em que se trata de submeter a prática à primazia do método. Por isso, é preciso retroceder a práticas históricas de valor constitutivo para a psicanálise ao visar os modos de recusa ou emprego do poder na mesma. É a isso que o autor se dedica, de maneira luminar, ao longo de seiscentas páginas, sem desconsiderar que as formas de exercício do poder a que remetem as práticas históricas examinadas não esgotam a questão na psicanálise. Nesse sentido, a psicanálise comparece não apenas como objeto da pesquisa que se empreende, mas como base da enunciação, na medida em que a formalização pretendida debruça-se igualmente sobre seus limites.

As práticas históricas aqui trabalhadas não se ordenam pela bipartição mais recorrente entre clínica e psicoterapia, mas se conjugam também com um terceiro termo presente nos textos de Freud - cura. No que concerne a essas distintas tradições, articuladas em torno de três termos, há uma tese posta de saída pelo autor que se desdobra em método na condução da investigação proposta: a heterogeneidade da prática psicanalítica, que se traduz em diversidade e riqueza, é presente na mesma porque já se encontra nas práticas que 1 Universidade do Estado do Rio de Janeiro, Rio de Janeiro-RJ, Brasil. 
a constituíram historicamente como tal. Clínica, psicoterapia e cura não estabelecem, para o autor, espaços simples, e sim um terreno de contradições e articulações discursivas diversas. Impõe-se, assim, que a relação da psicanálise com o contexto epistêmico, ético e político das práticas que a antecedem requer um trabalho topológico. O que encontramos neste ensaio é, portanto, uma aplicação da topologia à história.

Diante da pergunta subjacente a todo esforço de autoria em nosso campo - o que é a psicanálise? -, Dunker apresenta seus pressupostos. 0 primeiro deles concerne a que o problema de definir o que seja a prática psicanalítica comporta variantes em função de seus distintos desdobramentos. Ressalvada a heterogeneidade no interior da própria prática, restam os condicionantes do autor no que se refere à relação da psicanálise com as outras práticas. Por um lado, ao se pensar tal relação em termos de assimilações e recusas, ele sublinha como requisito não se ter aí uma equação de resto anulável. O recurso à topologia resguarda a dimensão atópica da psicanálise. Por outro lado, se não se trata de reduzir o novo ao já conhecido, o privilégio ao exame da constituição histórica assenta-se no motivo de a psicanálise não deixar de participar de outras formações discursivas.

Nesse sentido, Foucault é uma referência importante ao se valorizar a perspectiva genealógica contra uma apreensão homogeneizante da psicanálise enquanto formação discursiva. Dentro do mesmo horizonte crítico, cabe destacar a reserva do autor quanto ao emprego não comedido da ideia de corte quando se quer acentuar a autonomia da psicanálise. Ele alerta, de modo oportuno, que o uso excessivo de tal recurso para enfatizar o caráter inédito da psicanálise tende a limitar a reflexão sobre sua constituição histórica. Segundo o autor, ao se celebrar a novidade da psicanálise, se está, ao mesmo tempo, contribuindo para a esterilidade em reinventá-la, em fazê-la avançar, o que depende do retorno sobre sua constituição. Conjugada ao exame genealógico, a autonomização da psicanálise estará mais bem situada.

O que foi observado pode ser ainda pensado com referência ao âmbito estrito do poder, temática preconizada pelo autor. Ele nos adverte que a não consideração da constituição histórica da psicanálise nos manteria desavisados quanto à possibilidade da infiltração de formas de poder que a transformariam em outra coisa, ainda que supuséssemos recusá-las ou delas nos evadirmos. Tal recusa ou evasão não se sustenta por petição de princípio. Ao contrário, o que o autor nos mostra é que as soluções encontradas pela psicanálise para a sua transmissão podem assemelhar-se às que na tradição, por exemplo do cuidado de si, respaldaram o esvaziamento de uma experiência crítica com o poder em benefício de políticas associativas.

É ainda em relação à especificidade do problema do poder na psicanálise que se delimita o protagonismo de Lacan na obra. Este não se 
valida meramente em uma opção doutrinária, mas na evidência de que, mais do que qualquer outro, foi Lacan quem interpelou a formação da clínica psicanalítica do ponto de vista do poder, não apenas no âmbito da relação analítica, mas também quanto ao contexto institucional.Contudo, a analítica do poder permaneceu, afirma o autor, um veio pouco explorado na reflexão sobre a obra do psicanalista francês. A importância disso se acentua no fato de que aquilo na psicanálise cuja articulação não se esgota na perspectiva de sua constituição, portanto da negação necessária para que ela tenha se constituído, encontra-se, no ensino lacaniano, indexado de modo privilegiado na esfera política.

Ao se deter nesse resto da operação pela qual se articula a prática psicanalítica às práticas que a constituem historicamente, entra em cena ainda, como um limite à mesma, a questão da verdade. Isso porque, na ótica do autor, a psicanálise comportaria, quanto a ela, um regime próprio. Outrossim, é na relação com a verdade que se sustenta a legitimidade do poder na psicanálise. Trata-se aí de algo que o autor demarca desde o início, com o que segue de maneira ressaltada os caminhos, na constituição da psicanálise, da distinção entre eficácia simbólica e excelência simbólica, a segunda tendo por requisito a experiência com a verdade. Por tomar como norte o problema da autenticidade da sustentação de uma prática, passa, por exemplo, pela tragédia como matriz descritiva para a psicanálise, na medida em que lida com os fundamentos éticos do poder. Interessa ao autor, sobretudo, preservar a conjugação de ética e política que se expressa prioritariamente no espaço da cura.

O destaque dado à questão do poder acaba por estabelecer, para o que o autor engloba com o termo cura, uma posição não equivalente à das práticas formativas associadas às duas outras tradições. O escopo da cura é situado fora do espaço formado entre terapêutica e clínica por evocar a contradição nas diferentes estratégias pelas quais uma e outra denegaram sua relação com a política. Representada pela antiga tradição do cuidado de si, é no espaço da cura que o autor aloca a implicação, cara ao pensamento de uma política da psicanálise, entre a prática política e a relação de si para consigo. A política da psicanálise se demarcaria justamente pela desestabilização e contingência da separação entre ética e política, como também entre excelência e eficácia.

Tomada nesses termos, a política da psicanálise mostra-se oportuna em um contexto no qual o mestre contemporâneo, conjugação do tecnocientificismo com o capitalismo globalizante, comanda a imposição de protocolos a uma extensão sempre crescente de práticas. Dentro da racionalidade a que elas se veem convocadas, tem-se, no limite, a ética condicionada à eficácia: é ético se é eficaz. Em seu tempo, Freud já testemunhava a reivindicação às evidências de eficácia. Relata, em uma conferência, que a requisição à psicanálise para que oferecesse certo tipo de evidência de sua eficácia terapêutica revelava-se antiga:"em certa época, 
fazia-se contra a análise a queixa de que não podia ser tomada a sério, na qualidade de tratamento, de vez que não se atrevia a publicar estatísticas de seus êxitos" (Freud, 1933/1987, p. 186).

Quando não se engaja nessa via de demonstração da eficácia, mais do que indiferença com relação aos resultados terapêuticos da psicanálise, o que pauta Freud é perceber que tal procedimento implicaria obrigatoriamente uma redução da experiência. Em outro momento (Freud, 1926/1987), ele expressou sua precaução quanto à psicanálise ser submetida às regras formuladas para os métodos terapêuticos, dizendo querer sentir-se seguro de que a terapia não destruiria a ciência - a sua ciência bem entendido, a psicanálise. Há aí, portanto, implicação ética e política em associar a efetividade da prática à interrogação da verdade onde algo resiste. A supressão do que resiste ao terapêutico, à eficácia, à evidência revogaria a aposta nos efeitos de abrigar tal elemento irredutível.

Também na perspectiva de Christian Dunker, à arqueologia da psicanálise importam os fragmentos que podem questionar e reinventar o presente, os quais são buscados em superfícies que se expandem além do comum, em razão da erudição por ele demonstrada. Erudição cujo valor se complementa com a permanente verificação pelo autor - tarefa de que é também incumbido o leitor - do que se obtém de transmissão ao relacionar a psicanálise à história da medicina desde a Antiguidade grega, à tragédia, às tradições da retórica e da cura sui, a incursões na filosofia socrático-platônica e na que a antecedeu, a percursos nas obras de Descartes, Kant e Hegel. Um empreendimento vultoso que tem como prumo a orientação, com procedência psicanalítica, de incluir o limite do empreendimento em sua própria origem.

Já em Freud não se verifica qualquer pretensão de delimitar a psicanálise pela resultante da negação ou da assimilação do que já era conhecido. A escrita, no que é seguido por Dunker, não se reduz a dar forma a um conteúdo. Se, por um lado, há que se buscar palavras para escrever - sem o que cedemos ao apelo do inefável -, por outro lado, o próprio limite, a própria impossibilidade deve se encontrar incluída na escrita. Não por acaso, o autor indica reiteradamente que as proximidades ou negações que a constituição histórica da psicanálise evidencia não esgotam a questão. Em uma das muitas referências por ele examinadas, encontramos uma diretriz que, de certo modo, pauta o próprio trabalho empreendido no livro: no ceticismo recuperado por Montaigne tem-se a procura da verdade concomitante à afirmação de sua impossibilidade. Novamente reconhecemos o peso do que o autor associa à excelência simbólica.

A inexistência do compromisso em alcançar a integral sobreposição da experiência analítica pelas práticas formativas de que o livro trata - na topologia histórica predominam as descontinuidades e dispersões - segue a ideia de uma escrita que não consiste na abstração de uma realida- 
de. É antes o manejo dos termos que torna algo pensável, à condição de que o próprio limite, o real lacaniano que o autor cinge com propriedade, encontre-se em sua base. A investigação histórica da constituição da prática psicanalítica encontra-se articulada, como indicado, à retomada de seus fragmentos na estrutura. Não se trata, com isso, de apenas prevenir uma apreensão estritamente historiográfica da obra, mas do que o autor revela como the sendo fundamental: que a oposição entre estrutura e constituição histórica já seja, em nosso caso, em si mesma um problema.

\section{Referências}

Freud, S. (1987). A questão da análise leiga: conversações com uma pessoa imparcial. In S. Freud (Ed.), Edição standard brasileira das obras psicológicas completas de Sigmund Freud (J. Salomão, trad., Vol. 20, pp. 205-293). Rio de Janeiro, RJ: Imago. (Trabalho original publicado em 1926)

Freud, S. (1987). Novas conferências introdutórias sobre psicanálise. In S. Freud (Ed.), Edição standard brasileira das obras psicológicas completas de Sigmund Freud (J. Salomão, trad., Vol. 22, pp. 13-220). Rio de Janeiro, RJ: Imago. (Trabalho original publicado em 1933) 
Vinicius Darriba, Professor Adjunto da Universidade do Estado do Rio de Janeiro (UERJ), Programa de Pós-Graduação em Psicanálise (PGPSA). Endereço eletrônico: vdarriba@centroin.com.br

Recebido em: 23/05/2013

Aceito em: 9/06/2013 